\title{
Conjunctival transcriptome profiling of Solomon Islanders with active trachoma in the absence of Chlamydia trachomatis infection
}

Hristina Vasileva', Robert Butcher ${ }^{1 *} \mathbb{D}$, Harry Pickering ${ }^{1}$, Oliver Sokana ${ }^{2}$, Kelvin Jack ${ }^{2}$, Anthony W. Solomon ${ }^{1}$, Martin J. Holland ${ }^{1}$ and Chrissy h. Roberts ${ }^{1}$

\begin{abstract}
Background: Clinical signs of active (inflammatory) trachoma are found in many children in the Solomon Islands, but the majority of these individuals have no serological evidence of previous infection with Chlamydia trachomatis. In Temotu and Rennell and Bellona provinces, ocular infections with C. trachomatis were seldom detected among children with active trachoma; a similar lack of association was seen between active trachoma and other common bacterial and viral causes of follicular conjunctivitis. Here, we set out to characterise patterns of gene expression at the conjunctivae of children in these provinces with and without clinical signs of trachomatous inflammationfollicular (TF) and C. trachomatis infection.

Methods: Purified RNA from children with and without active trachoma was run on Affymetrix GeneChip Human Transcriptome Array 2.0 microarrays. Profiles were compared between individuals with ocular $C$. trachomatis infection and TF (group Dl; $n=6$ ), individuals with TF but no $C$. trachomatis infection (group $D ; n=7$ ), and individuals without TF or $C$. trachomatis infection (group $N ; n=7$ ). Differential gene expression and gene set enrichment for pathway membership were assessed.

Results: Conjunctival gene expression profiles were more similar within-group than between-group. Principal components analysis indicated that the first and second principal components combined explained almost $50 \%$ of the variance in the dataset. When comparing the DI group to the $\mathrm{N}$ group, genes involved in T-cell proliferation, B-cell signalling and CD8+ T cell signalling pathways were differentially regulated. When comparing the DI group to the D group, CD8+ T-cell regulation, interferon-gamma and IL17 production pathways were enriched. Genes involved in RNA transcription and translation pathways were upregulated when comparing the $D$ group to the N group.

Conclusions: Gene expression profiles in children in the Solomon Islands indicate immune responses consistent with bacterial infection when TF and C. trachomatis infection are concurrent. The transcriptomes of children with TF but without identified infection were not consistent with allergic or viral conjunctivitis.
\end{abstract}

Keywords: Solomon Islands, Trachoma, Transcriptome, Chlamydia trachomatis

\footnotetext{
*Correspondence: robert.butcher@lshtm.ac.uk

${ }^{1}$ Clinical Research Department, London School of Hygiene \& Tropical

Medicine, Keppel Street, London WC1E 7HT, UK

Full list of author information is available at the end of the article
} 


\section{Background}

Trachoma, caused by Chlamydia trachomatis $(C t)$, is the most common infectious cause of blindness worldwide, responsible for an estimated 1.9 million cases of blindness or visual impairment [1]. Ocular infection with $\mathrm{Ct}$ predominantly occurs in young children and triggers follicular and papillary inflammation. Repeated rounds of infection, inflammation and disease resolution lead to deposition of scar tissue on the conjunctiva (trachomatous scarring, TS) which accumulates with time; ultimately distorting the eyelid and, in severe cases, bringing the eyelashes into contact with the globe of the eye (trachomatous trichiasis, TT). Abrasion by these lashes can cause opacity (corneal opacity, CO) and blindness. Trachoma is treated with a package of interventions aimed at controlling infection and reducing the risk of blindness from TT, collectively termed the SAFE strategy. These include eyelid Surgery for those with TT, community-wide Antibiotic distribution, promotion of Facial cleanliness and Environmental improvement [2].

In a 2013 survey of children aged 1-9 years in Temotu and Rennell and Bellona provinces of the Solomon Islands, we found that more than a quarter (26.1\%) of those examined had the active (inflammatory) trachoma sign trachomatous inflammation-follicular (TF). This level of endemicity was high enough to warrant treatment of the whole population by mass drug (azithromycin) administration, but the prevalence of the more severe active trachoma sign trachomatous inflammation-intense (TI; $0.2 \%$ ) and ocular $C t$ infection (1.3\%) was unusually low given the TF prevalence [3]. In two consecutive surveys of this population we consistently found that over $90 \%$ of TF cases occurred in individuals who had no PCR detectable ocular $C t$ infection. We also assessed the blood levels of anti-Pgp3 antibodies, a putative serological marker of lifetime $C t$ exposure [4]. We found that TF was not associated with Pgp3 seropositivity. These data suggested that the majority of TF cases that we identified were in individuals who were very unlikely to have ever been exposed to any form of $C t$ infection [5]. When we tested for the presence of several other infectious micro-organisms that are known to be able to cause symptoms of follicular inflammation (Haemophilus influenzae, Streptococcus pneumoniae, Moraxella catarrhalis, Staphylococcus spp. and Adenoviridae), we found no association between TF and any of these bacteria and viruses. A broad screen for changes in bacterial communities of the conjunctiva in TF cases was similarly null [6]. It could therefore be reasonably concluded that TF in this population is unlikely to be linked to any bacterial infection.

The grading of TF was conducted by graders trained to the same international standards as graders in other countries, giving us no reason to suspect the TF phenotype in the Solomon Islands is different to that in trachoma-endemic populations elsewhere in the world [3]. However, we observed very little TS in the Solomon Islands [5]. Therefore, an important question that emerges from our work is whether there are differences in the underlying immune response that could explain why, in the Solomon Islands, highly prevalent TF does not seem to be concurrent with the same burden of blinding sequelae of trachoma as in other countries.

Previous work has described the typical host immune response to ocular infection with $C t$, a response that can persist for weeks to months after the infection is resolved [7]. While the frequency and duration of $C t$ infection decrease with age, inflammation can be found in a significant fraction of older people, and is associated with progression of scarring $[7,8]$. The clearance of $\mathrm{Ct}$ infection is generally accepted to be mediated by interferon gamma (IFNY) [9-11] with epithelial and lymphoid cells generating a strong pro-inflammatory Type 1 response that includes production of growth factors, such as platelet-derived growth factor (PDGF), connectivetissue growth factor (CTGF) and tumour necrosis factor alpha (TNF $\alpha)$ [12-15]. Prolonged activation of these responses leads to the formation of the lymphoid follicles that characterise TF. Studies have also shown upregulation of major histocompatibility complex (MHC) class I expression, the induction of MHC class II in cells in which it is normally absent, as well as the expression of genes typical of neutrophils and natural killer (NK) cell cytotoxicity $[13,16]$. Other types of conjunctivitis (i.e. those not caused by $C t$ infection) have different underlying immune pathologies and are characterised by quite distinct transcriptomic signatures. Allergic conjunctivitis, for instance, is characterised by eosinophilic inflammation, mast cell degranulation, upregulation of adhesion molecules and production of chemokines [17-19]. Conversely, in vitro transcriptional profiling studies of adenoviral infection of human epithelial cells indicate dominance of antiviral and type-one interferon-associated pathways [20].

We hypothesised that gene expression profiles of TF in the Solomon Islands could help us to determine whether TF in children from the Solomon Islands is caused by bacteria, viruses or allergens.

\section{Methods}

\section{Specimen collection}

Specimens were collected during a population-based prevalence survey for trachoma in Temotu and Rennell and Bellona provinces of the Solomon Islands which took place in 2013 [3]. Clinical grades were assigned in the field by Global Trachoma Mapping Project-certified graders according to the WHO simplified grading scheme [21, 22]. All clinical data and methods relating to the 2013 survey have been published elsewhere [3]. Briefly, we used polyester-coated cotton swabs to collect 
conjunctival specimens from 1002 1-9-year-olds. Swabs were collected from the everted right conjunctiva and placed immediately into $300 \mu \mathrm{l}$ RNAlater, then kept cool in the field and frozen within $48 \mathrm{~h}$ of collection. Specimens were shipped on dry ice to the UK for processing.

\section{Case-control selection}

From the whole population sample, three subsets of specimens were selected for the microarray-based gene expression profiling experiment. Group N $(n=7)$ were children who had neither TF, nor $C t$ infection [3], nor any of other common ocular infections (as listed in the introduction) [6]. Group D $(n=7)$ were children who did have TF, but had neither $C t$ nor any of the other infections.

Two years after the initial survey, all individuals in groups $\mathrm{D}$ and $\mathrm{N}$ were revisited by chance during a serological survey and were tested for evidence of prior $C t$ infections with an anti-Pgp3 ELISA test [5]. All members of groups $\mathrm{D}$ and $\mathrm{N}$ were seronegative at that time, suggesting that no member of either group had previously been infected with $C t$. The third group DI $(n=6)$ had both clinical signs of TF (but not TI) and current ocular $C t$ infection during the 2013 survey. The mean $C t$ load in the 6 DI conjunctival samples was 338 omcB copies/ $\mu \mathrm{l}$ (range: $0.4-1121 \mathrm{omcB}$ copies/ $\mu \mathrm{l}$ ). The detected strain in all 6 DI samples were serovar $C$ according to ompA sequence, and were most closely related to $C t$ A/HAR13 within the T2 ocular clade when aligned at the whole-genome level [3]. We had very few $C t$ infection cases to choose from, so we were unable to stringently filter the DI group to ensure that no 'other infections' were present. Three of the DI group members had no other infections besides $C t$, one had $S$. pneumoniae present, one had $H$. influenzae, and one had Adenovirus and $H$. influenzae present. All of these infections were low load $(<5$ copies $/ \mu \mathrm{l})$. None of the six members of group DI participated in the 2015 follow-up survey. Participants were age- and gender-matched between groups (Kruskall-Wallis test, $\chi^{2}=0.31804, d f=2, P=0.853$ and $\chi^{2}=2.6412, d f=2, P=0.267$, respectively).

\section{RNA extraction and quantification}

DNA and total RNA from each sample were simultaneously extracted using the Qiagen AllPrep Mini protocol (Qiagen, Hilden, Germany). DNA extracts were tested for $C t$ infection using a droplet digital PCR (ddPCR) assay [23] which we have previously used in both high $[24,25]$ and low endemicity settings $[3,26]$. The diagnostic performance of the in-house ddPCR assay, published elsewhere, has a demonstrated sensitivity of $97.1 \%$ and specificity of $90.0 \%$ in low endemicity areas [27]. Purified RNA was stored at $-80{ }^{\circ} \mathrm{C}$ before testing. The quantity and quality of RNA was calculated using
Agilent RNA 6000 Pico Assay according to the manufacturer's protocol (Agilent, Santa Clara, USA).

\section{Probe library preparation}

RNA samples were normalised and used as a template for the generation of cDNA using NuGEN Ovation Pico WTA System V2 protocol (NuGEN, Leek, Netherlands). cDNA was amplified and purified using Agencourt RNAClean XP (Beckman Coulter, High Wycombe, UK) followed by QIAGEN QIAquick PCR Purification (Qiagen, Hilden, Germany).

cDNA fragmentation and labelling was performed according to FL-Ovation ${ }^{\text {TM }}$ cDNA Biotin Module V2 protocol (NuGEN, Leek, Netherlands). Biotinylated cDNA was hybridised to GeneChip HTA 2.0 microarrays according to the NuGEN Hybridization, Cocktail Assembly and Fluidics Protocol for single arrays (NuGEN, Leek, Netherlands). The hybridized arrays were washed and stained with streptavidin-phycoerythrin (SAPE) in a Fluidex GeneChip 450 according to the GeneChip ${ }^{\circ}$ Expression Analysis protocol (Thermo Fisher Scientific, Hemel Hempsted, UK). Goat anti-biotin-SAPE antibodies (IgG) were used for signal amplification.

\section{Microarray data processing}

The GeneChip HTA 2.0 array contains approximately 1.7 million probe sets, represented by 70,523 human transcript clusters [28]. Analysis of array data was conducted using Bioconductor and $\mathrm{R}$ software packages [29, 30]. Mean microarray average plots were visually inspected to ensure consistency and quality of hybridization intensity between arrays. Array data files were normalized using Robust Multichip Average (RMA) algorithms from the Bioconductor package "oligo" [31]. Transcript clusters were annotated using the 'hta20transcriptcluster.db' Bioconductor package. Normalized transcript clusters without annotation information, those with no detected signal and array endogenous controls were discarded from the overall data set. Where more than one transcript cluster mapped to a single accession number, the transcript cluster with the highest fluorescence intensity was retained and the others discarded. Of the resultant transcript clusters, those with an RMA-normalised intensity interquartile range of $<0.1$ across all samples were also removed [30].

\section{Identification of differentially expressed genes}

Group mean hybridization intensities of each transcript were compared in a pairwise manner between the DI, D and $\mathrm{N}$ sample groups, applying empirical Bayes moderated t-test for mean difference [32] using the Bioconductor package "limma" [33]. To account for multiple testing of large number of variables, a corrected $P$-value for each transcript was obtained by subjecting the $P$-values 
from each comparison to a permutation analysis [34]. Transcript clusters with a corrected $P$-value lower than the selected threshold of $<0.05$ for each comparison were considered differentially expressed (DE) [35]. Directionality of DE gene regulation was determined by gene $\log 2$ fold change $(\log 2 \mathrm{FC})$ of expression fluctuating above (upregulated) and below (downregulated) $\log 2 \mathrm{FC}=1 . \mathrm{DE}$ genes from all three comparisons (DI vs D, DI vs N, D vs N) were combined for the purposes of visualizing the differences in global gene expression between groups. Principal components analysis (PCA) was used to visualise differences in transcriptomes between samples according to variance between gene expression levels of total DE genes [36]. PCA was used to identify whether the phenotypic groups could be separated according to variance in total DE genes expression profiles. Group separation was tested using ordinal logistic regression, using the "MASS" package in R [37].

\section{Biological function of differentially expressed genes}

Lists of DE gene GenBank accession numbers were subjected to Gene Ontology (GO) terms analysis, using Database for Annotation, Visualization and Integrated Discovery (DAVID) v6.8 [38]. GO terms were considered statistically significant based on Benjamini's adjusted $P$ value $<0.05$. The top five statistically significant genetic pathways for the DE genes in each comparison were identified using Kyoto Encyclopaedia of Genes and Genomes (KEGG) bioinformatics database [39].

\section{Results and Discussion}

Following comparison of transcript clusters hybridisation intensities between groups, a combined total of $7761 \mathrm{DE}$ genes were identified. The number of genes per group is summarized in Table 1 and the comparison of DE gene expression across all samples is visualised as a heat map in Fig. 1a. Most samples appeared to be more similar within-group than between-groups, with some exceptions (samples DI3, DI4, N1 and N2). There were no significant differences between chlamydial load (Mann-Whitney U-test, $U=3, n_{1}=2, n_{2}=4, P=0.8$ ), nor between the age or gender of the participants from whom samples DI3 and DI4 came from, compared with the rest of the DI group specimens. The same was

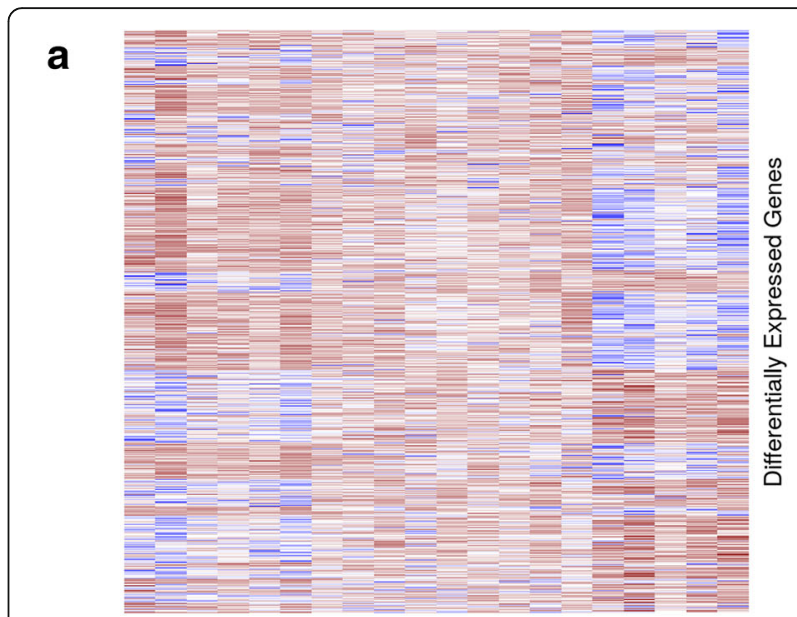

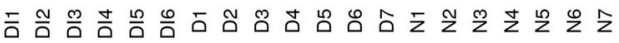
Sample Name

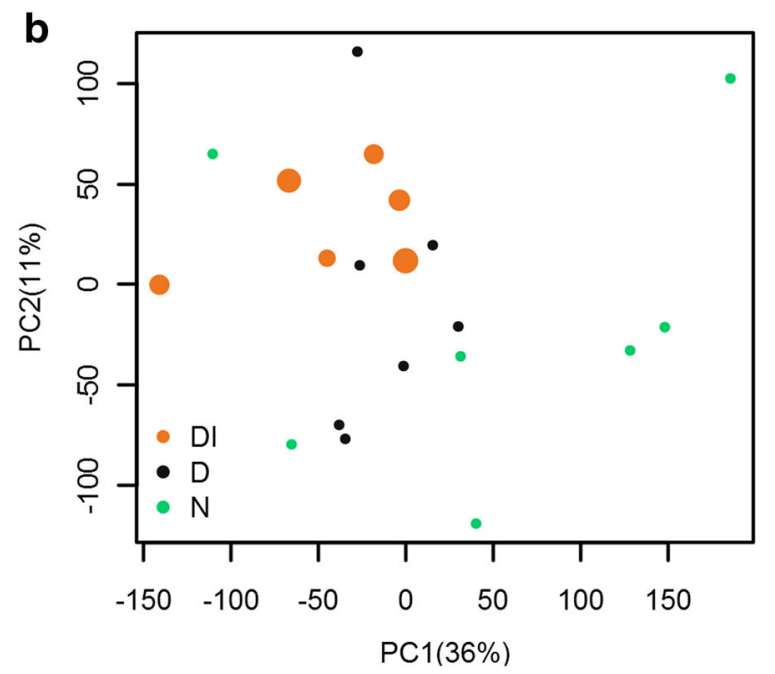

Fig. 1 a Heat map visually representing the gene expression intensity of total differentially expressed genes, $(n=7761)$ in each array sample. Red indicates high expression, blue indicates low expression. b Principal components analysis of differentially expressed genes in children with and without TF and Ct infection in the Solomon Islands $(n=20)$. Point colour indicates the clinical phenotype whilst the size of the point is proportional to the load of $\mathrm{Ct}$ infection in specimens within the DI group

Table 1 Differentially expressed (DE) genes in each group comparison, separated according to the direction and magnitude of change

\begin{tabular}{lllll}
\hline & Comparison & DI vs D $(n=2368)$ & DI vs N $(n=6371)$ & D vs N (n=1933) \\
\hline Upregulated genes & $n(\%)$ & $1388(58.6)$ & $2777(43.6)$ & $700(36.2)$ \\
& $\log 2 F C$, mean (min-max) & $0.378(0.067-2.971)$ & $0.437(0.072-2.694)$ & $0.322(0.064-1.477)$ \\
Downregulated genes & $n(\%)$ & $980(41.4)$ & $3594(56.4)$ & $1233(63.8)$ \\
& $\log 2 F C$, mean (min-max) & $-0.346(-3.686--0.065)$ & $-0.294(-3.901--0.054)$ & $-0.230(-1.436--0.054)$ \\
\hline
\end{tabular}


observed for samples $\mathrm{N} 1$ and N2 compared with the other samples from the $\mathrm{N}$ group. As no significant differences in the demographics of the group members that might account for the observed differences in gene expression pattern can be identified, we suggest this is likely to be due to natural within-group heterogeneity. Figure 1b shows a bi-plot of the first two principal components (PCs) which cumulatively describe 47\% (PC1: $36 \%, \mathrm{PC} 2: 11 \%)$ of the total between-group variance in gene expression. Each coloured point represents one of the specimens. There are visible separations between clusters of specimens which have similar phenotypes.

We observed substantial gene expression profile differences between the DI, D and N groups (Fig. 1). The KEGG pathway analysis is summarised in Table 2 . Our data show that the most enriched pathways observed when comparing the DI group with the $\mathrm{D}$ and $\mathrm{N}$ groups are closely linked to key elements of the immune response, including IL17 and IFNY production, genes controlling T-cell proliferation/response and B-cell signalling. The D group, which had no evidence of current or previous $C t$ infection, was not enriched for the same pathways when compared to the N group. Surprisingly, individuals with visible subconjunctival lymphoid follicles had no enrichment of pathways related to lymphocyte activation, nor upregulated genes associated with activation and recruitment of NK and dendritic cells (CCL18), fundamental for TF [13]. In the $C t$-infected (DI) group we saw some patterns of

Table 2 Biological pathways (GO terms and KEGG pathways) showing significant enrichment across three between-group comparisons

\begin{tabular}{|c|c|c|c|c|c|}
\hline $\begin{array}{l}\text { Comparison } \\
\text { (No. of genes) }\end{array}$ & Principal GO terms & Fold enrichment & Adjusted $P$-value & Principal KEGG pathways & $P$-value \\
\hline \multirow[t]{7}{*}{$\begin{array}{l}\text { DI vs } D \\
(n=2368)\end{array}$} & GO:0039692: ssRNA viral replication & 6.93 & $2.23 \times 10^{-2}$ & $\begin{array}{l}\text { hsa04658: Th1 and Th2 } \\
\text { cell differentiation }\end{array}$ & $6.80 \times 10^{-7}$ \\
\hline & $\begin{array}{l}\text { GO:2,001,185: regulation of CD8+ } \\
\text { T-cells }\end{array}$ & 6.93 & $2.23 \times 10^{-2}$ & hsa04110: Cell cycle & $4.33 \times 10^{-6}$ \\
\hline & GO:0072643: IFNy secretion & 5.78 & $2.34 \times 10^{-3}$ & hsa05203: Viral carcinogenesis & $1.40 \times 10^{-4}$ \\
\hline & $\begin{array}{l}\text { GO:0007076: mitotic chromosome } \\
\text { condensation }\end{array}$ & 5.39 & $2.70 \times 10^{-2}$ & hsa04114: Oocyte meiosis & $2.19 \times 10^{-4}$ \\
\hline & GO:0046633: T-cell proliferation & 5.33 & $2.65 \times 10^{-2}$ & $\begin{array}{l}\text { hsa04612: Antigen processing } \\
\text { and presentation }\end{array}$ & $3.16 \times 10^{-4}$ \\
\hline & $\begin{array}{l}\text { GO:0032620: interleukin-17 } \\
\text { production }\end{array}$ & 4.16 & $2.30 \times 10^{-2}$ & hsa05166: HTLV-I infection & $1.33 \times 10^{-3}$ \\
\hline & GO:1,901,976: regulation of cell cycle & 3.50 & $3.65 \times 10^{-2}$ & hsa05340: Primary immunodeficiency & $3.12 \times 10^{-03}$ \\
\hline \multirow[t]{7}{*}{$\begin{array}{l}\text { DI vs N } \\
(n=6371)\end{array}$} & GO:0036037: CD8+ T-cell activation & 2.88 & $3.59 \times 10^{-3}$ & $\begin{array}{l}\text { hsa04750: Inflammatory mediator } \\
\text { regulation of TRP channels }\end{array}$ & $1.22 \times 10^{-3}$ \\
\hline & $\begin{array}{l}\text { GO:0006270: DNA replication } \\
\text { initiation }\end{array}$ & 2.41 & $4.18 \times 10^{-3}$ & hsa03030: DNA replication & $2.06 \times 10^{-3}$ \\
\hline & GO:0045047: Protein targeting to ER & 2.07 & $1.11 \times 10^{-5}$ & hsa03040: Spliceosome & $2.06 \times 10^{-3}$ \\
\hline & GO:0019080: Viral gene expression & 1.98 & $4.53 \times 10^{-9}$ & $\begin{array}{l}\text { hsa04612: Antigen processing and } \\
\text { presentation }\end{array}$ & $2.38 \times 10^{-3}$ \\
\hline & $\begin{array}{l}\text { GO:0050853: B-cell receptor signalling } \\
\text { pathway }\end{array}$ & 1.83 & $3.19 \times 10^{-2}$ & $\begin{array}{l}\text { hsa04925: Aldosteron synthesis and } \\
\text { secretion }\end{array}$ & $3.02 \times 10^{-3}$ \\
\hline & GO:0048477: oogenesis & 1.74 & $2.60 \times 10^{-2}$ & hsa04658: Th1 and Th2 cell differentiation & $5.50 \times 10^{-3}$ \\
\hline & GO:0042098: T-cell proliferation & 1.65 & $6.17 \times 10^{-4}$ & hsa04110: Cell cycle & $5.70 \times 10^{-3}$ \\
\hline \multirow{7}{*}{$\begin{array}{l}\text { D vs N } \\
(n=1933)\end{array}$} & GO:0045047: Protein targeting to ER & 6.59 & $2.41 \times 10^{-20}$ & hsa03010: Ribosome & $1.18 \times 10^{-11}$ \\
\hline & GO:0019083: Viral gene expression & 4.37 & $1.89 \times 10^{-18}$ & $\begin{array}{l}\text { hsa04612: Antigen processing and } \\
\text { presentation }\end{array}$ & $1.34 \times 10^{-3}$ \\
\hline & GO:0042255: ribosome assembly & 3.92 & $9.50 \times 10^{-4}$ & hsa03030: DNA replication & $2.42 \times 10^{-2}$ \\
\hline & GO:0042254: ribosome biogenesis & 2.50 & $8.99 \times 10^{-8}$ & hsa03040: Spliceosome & $5.53 \times 10^{-2}$ \\
\hline & $\begin{array}{l}\text { GO:0043043: peptide biosynthetic } \\
\text { process }\end{array}$ & 1.92 & $1.37 \times 10^{-6}$ & hsa05332: Graft-versus-host disease & $5.53 \times 10^{-2}$ \\
\hline & GO:0006396: RNA processing & 1.81 & $2.26 \times 10^{-7}$ & hsa05416: Viral myocarditis & $8.33 \times 10^{-2}$ \\
\hline & $\begin{array}{l}\text { GO:0033365: Protein localization } \\
\text { to organelle }\end{array}$ & 1.63 & $1.62 \times 10^{-4}$ & & \\
\hline
\end{tabular}


pathway enrichment that closely resembled data from other trachoma-endemic populations $[8,13]$. However, whilst IL17 and IFN $\gamma$ pathways were upregulated in the Solomon Islands, key pro-fibrotic markers and genes encoding extracellular matrix molecules ( $M M P 7, M M P$, $M M P 12)$ were not found to be differentially regulated, nor were their associated pathways enriched [13]. These pathways are typical of scarring disease, but are also upregulated during and after $C t$ infection in young people with inflammatory trachoma [40].

Previous studies have shown that thymic stromal lymphoprotein (TSLP), IL-4, IL-5 and $I L-13$ are upregulated during episodes of allergic or seasonal conjunctivitis [41], but these were not significantly differentially regulated in the $\mathrm{D}$ group when compared to the $\mathrm{N}$ group nor the DI group when compared to the D group. We did not identify any key pathways associated with eosinophilic inflammation, IgE release or degranulation of mast cells and we therefore do not suspect allergic responses to be playing a significant role in the TF phenotype in these children. The predominant pathways that showed highly significant enrichment in the D group, when compared with the $\mathrm{N}$ group, were viral gene expression pathways as well as protein biosynthesis pathways centring around ribosome function. However, anti-viral immunity and type one interferon-dependent pathways were not enriched according to this analysis. Viral pathways were also enriched in the DI group when compared to the $\mathrm{N}$ and $\mathrm{D}$ groups, although these were less significant. There is deep redundancy and overlap of gene content in the GO and KEGG pathways, which means that their names can often be misleading with regards to their roles in a specific clinical context. On that basis, we do not have strong evidence that an as-yet uncharacterised viral infection may be responsible for the observed discrepancy between phenotype and $C t$ infection. This study was limited by small sample size and in some cases the additional diagnosis of other ocular infections that can cause TF-like clinical signs. However, the natural heterogeneity of the data is typical of complex human disease studies and the transcriptional profiles of those with disease and $C t$ infection were sufficiently similar to those seen in other populations.

The World Health Organization guidelines for implementing mass drug administration (MDA) are based largely on TF prevalence. We have previously argued that whilst the Solomon Islands has sufficiently prevalent clinical signs (TF) of trachoma to qualify for implementation of MDA, the prevalence of infection and trichiasis [3, 5], as well as severe scarring and serological signs of prior infection [6] are all too low to suggest that clinical diagnosis with TF has the necessary specificity to be used as an indicator of need for intervention in this population. By showing that the transcriptional profile of TF (Ct uninfected) cases in the Solomon Islands share some, but not all, the components of typical trachoma responses seen elsewhere, the current findings add to those of our previous studies to suggest that the majority of TF disease we observe there is not related to $C t$. We believe that there is potential that similar disease could occur elsewhere and would recommend that a diagnostic test for ocular infection should be considered for routine use in combination with clinical signs of the disease, in order to better inform the decision to treat a population with MDA.

\section{Conclusions}

Our recent studies identified that the majority of TF disease in the Solomon Islands could be attributed to neither $C t$ [3], nor any of several common ocular microbes, nor polymicrobial community [6]. We hypothesised that TF in the absence of current $C t$ infection in the Solomon Island population would have a transcriptional profile that could indicate either an allergic or viral trigger. The host responses we measured did not provide any indication for the involvement of an allergic response, nor was there convincing evidence for a response to a viral infection. The results suggest that further studies in to the aetiology of disease in this context are warranted.

\begin{abstract}
Abbreviations
CO: Corneal opacity; Ct: Chlamydia trachomatis; D: Study participant group with TF but no Ct infection; ddPCR: Droplet digital polymerase chain reaction; DE: Differentially expressed; DI: Study participant group with concurrent TF and Ct infection; GO: Gene Ontology; KEGG: Kyoto Encyclopaedia of Genes and Genomes; Log2FC: Log (base 2) fold change; MDA: Mass drug administration; N: Study participant group with neither TF nor Ct infection; PC: Principal Component; PCA: Principal Components Analysis; RMA: Robust multichip average; SAFE: Surgery, Antibiotics, promotion of Facial hygiene and Environmental improvement;

TF: Trachomatous inflammation-follicular; TI: Trachomatous inflammationintense; TS: Trachomatous scarring; T: Trachomatous trichiasis; WHO: World Health Organization
\end{abstract}

\section{Acknowledgements}

We would like to thank Dr David Chambers (UK Bioinformatics, London, UK) for his support with the RNA library preparation and microarray processing. We are grateful to Eric Kalae, Leslie Sui and Charles Russell for their roles in the collection of the Solomon Island samples used in this study. We would also like to thank the residents of Temotu, Rennell and Bellona who took part in this survey. The findings and conclusions in this report are those of the authors and do not necessarily represent the official positions of the institutions with which they are affiliated.

\section{Funding}

The fieldwork was co-funded by United Kingdom's Department for International Development Global Trachoma Mapping Project grant (ARIES: 203145) to Sightsavers and by the Fred Hollows Foundation Australia (FHF 1041). The laboratory work, RB's salary and AWS's salary was supported by the Fred Hollows Foundation (FHF 1954-0) and the Wellcome Trust (098521). HP was supported by Bloomsbury Colleges Research student scholarship. MJH was supported by the Wellcome Trust (0973330/Z/11/Z). ChR was supported by the Wellcome Trust Institutional Strategic Support Fund (105609/ Z/14/Z)

Availability of data and materials

The raw data obtained for the 20 arrays were deposited in the NCBI archive (www.ncbi.nlm.nih.gov/geo/) Gene Expression Omnibus under the accession number GSE106961. 


\section{Authors' contributions}

Conceived the study: HV, RB, OS, AWS, MJH and ChR. Obtained funding: RB, AWS and ChR. Conducted fieldwork: RB, OS, KJ and AWS. Analysed the data: $H V, R B, H P, M J H$ and ChR. Prepared the manuscript: HV, RB, HP, MJH and ChR. All authors read and approved the final manuscript.

\section{Ethics approval and consent to participate}

The study adhered to the tenets of the Declaration of Helsinki. The study was approved by the London School of Hygiene \& Tropical Medicine Ethics Committee (6319, 10145 and 13460; approved 21/12/2012, 13/06/2015 and 10/05/2017, respectively) and the Solomon Islands National Health Research Ethics Committee (HRC13/18; approved 23/08/2013). Written consent to take part was granted on behalf of each child by a parent or guardian

\section{Consent for publication}

Not applicable.

\section{Competing interests}

The authors declare that they have no competing interests.

\section{Publisher's Note}

Springer Nature remains neutral with regard to jurisdictional claims in published maps and institutional affiliations.

\section{Author details}

Clinical Research Department, London School of Hygiene \& Tropical Medicine, Keppel Street, London WC1E 7HT, UK. ${ }^{2}$ Eye Department, Solomon Islands Ministry of Health and Medical Services, PO Box 349, Honiara, Solomon Islands.

Received: 17 November 2017 Accepted: 29 January 2018

Published online: 21 February 2018

\section{References}

1. Bourne RA, Stevens GA, White RA, Smith JL, Flaxman SR, Price $H$, et al. Causes of vision loss worldwide, 1990-2010: a systematic analysis. Lancet Glob Heal. 2013;1(6):e339-49.

2. World Health Organization. Report of the 2nd global scientific meeting on trachoma. Geneva: WHO; 2003.

3. Butcher RMR, Sokana O, Jack K, Macleod CK, Marks ME, Kalae E, et al. Low prevalence of conjunctival infection with Chlamydia trachomatis in a treatment-naïve trachoma-endemic region of the Solomon Islands. PLoS Negl Trop Dis. 2016;10(9):e0004863.

4. Goodhew EB, Priest JW, Moss DM, Zhong G, Munoz B, Mkocha H, et al. CT694 and pgp3 as serological tools for monitoring trachoma programs. PLoS Negl Trop Dis. 2012;6(11):e1873.

5. Butcher R, Sokana O, Jack K, Sui L, Martin DL, Burton MJ, et al. Age-specific prevalence of anti-Pgp3 antibodies and conjunctival scarring in the Solomon Islands. bioRXiv; 2017. p. 141135.

6. Butcher RMR, Sokana O, Jack K, Kalae E, Sui L, Russell C, et al. Active trachoma cases in the Solomon Islands have varied polymicrobial community structures but do not associate with individual non-chlamydial pathogens of the eye. Front Med. 2018;4:251.

7. Bailey R, Duong T, Carpenter R, Whittle H, Mabey D. The duration of human ocular Chlamydia trachomatis infection is age dependent. Epidemiol Infect. 1999:123(3):479-86.

8. Hu VH, Holland MJ, Burton MJ. Trachoma: protective and pathogenic ocular immune responses to Chlamydia trachomatis. PLoS Negl Trop Dis. 2013;7(2): e2020.

9. Rapoza P, Tahija S, Carlin J, Miller S, Padilla M, Byrne G. Effect of interferon on a primary conjunctival epithelial cell model of trachoma. Invest Ophthalmol Vis Sci. 1991;32(11):2919-23.

10. Cohen CR, Koochesfahani KM, Meier AS, Shen C, Karunakaran K, Ondondo B, et al. Immunoepidemiologic profile of Chlamydia trachomatis infection: importance of heat-shock protein 60 and interferon-gamma. J Infect Dis 2005;192(4):591-9.

11. Faal N, Bailey RL, Sarr I, Joof H, Mabey DCW, Holland MJ. Temporal cytokine gene expression patterns in subjects with trachoma identify distinct conjunctival responses associated with infection. Clin Exp Immunol. 2005; 142(2):347-53.
12. Abu el-Asrar AM, Geboes K, Tabbara KF, Al-Kharashi SA, Missotten L, Desmet $\mathrm{V}$. Immunopathogenesis of conjunctival scarring in trachoma. Eye (Lond). 1998;12(Pt 3a):453-60

13. Natividad A, Freeman TC, Jeffries D, Burton MJ, Mabey DCW, Bailey RL, et al. Human conjunctival transcriptome analysis reveals the prominence of innate defense in Chlamydia trachomatis infection. Infect Immun. 2010; 78(11):4895-911.

14. Rasmussen SJ, Eckmann L, Quayle AJ, Shen L, Zhang YX, Anderson DJ, et al. Secretion of proinflammatory cytokines by epithelial cells in response to Chlamydia infection suggests a central role for epithelial cells in chlamydial pathogenesis. J Clin Invest. 1997;99(1):77-87.

15. Burton MJ, Ramadhani A, Weiss HA, Hu V, Massae P, Burr SE, et al. Active trachoma is associated with increased conjunctival expression of IL17A and profibrotic cytokines. Infect Immun. 2011;79(12):4977-83.

16. Mabey D, Bailey R, Dunn D, Jones D, Williams J, Whittle $H$, et al. Expression of MHC class II antigens by conjunctival epithelial cells in trachoma: implications concerning the pathogenesis of blinding disease. J Clin Pathol. 1991;44(4):285-9.

17. Galicia-Carreón J, Santacruz C, Ayala-Balboa J, Robles-Contreras A, PerezTapia S, Garfias Y, et al. An imbalance between frequency of CD4+CD25 +FOXP3+ regulatory T cells and CCR4+ and CCR9+ circulating helper T cells is associated with active perennial allergic conjunctivitis. Clin Dev Immunol. 2013;2013:919742.

18. Ebihara N, Matsuda A, Seto T, Ohtomo K, Funaki T, Takai T, et al. The epithelium takes center stage in allergic keratoconjunctivitis. Cornea. 2010;29(11):S41-7.

19. La Rosa M, Lionetti E, Reibaldi M, Russo A, Longo A, Leonardi S, et al. Allergic conjunctivitis: a comprehensive review of the literature. Ital J Pediatr. 2013:39:18.

20. Harvey S, Romanowski E, Yates K, Gordon Y. Adenovirus-directed ocular innate immunity: the role of conjunctival defensin-like chemokines (IP-10, ITAC) and phagocytic human defensin-alpha. Investig Ophthalmol Vis Sci. 2005:46(10):3657-65.

21. Solomon AW, Pavluck AL, Courtright P, Aboe A, Adamu L, Alemayehu W, et al. The global trachoma mapping project: methodology of a 34-country population-based study. Ophthalmic Epidemiol. 2015;22(3):214-25.

22. Thylefors B, Dawson CR, Jones BR, West SK, Taylor HR. A simple system for the assessment of trachoma and its complications. Bull World Health Organ. 1987:65(4):477-83.

23. Roberts $\mathrm{CH}$, Last A, Molina-Gonzalez S, Cassama E, Butcher R, Nabicassa M, et al. Development and evaluation of a next-generation digital PCR diagnostic assay for ocular Chlamydia trachomatis infections. J Clin Microbiol. 2013;51(7):2195-203.

24. Cama A, Müller A, Taoaba R, Butcher RMR, Itibita I, Migchelsen SJ, et al. Prevalence of signs of trachoma, ocular Chlamydia trachomatis infection and antibodies to Pgp3 in residents of Kiritimati Island, Kiribati. PLoS Negl Trop Dis. 2017;11(9):e0005863.

25. Last AR, Burr SE, Weiss HA, Harding-Esch EM, Cassama E, Nabicassa M, et al. Risk factors for active trachoma and ocular Chlamydia trachomatis infection in treatment-naïve trachoma-hyperendemic communities of the Bijagós Archipelago, Guinea Bissau. PLoS Negl Trop Dis. 2014;8(6):e2900.

26. Macleod CK, Butcher R, Mudaliar UU, Natutusau K, Pavluck AL, Willis R, et al. Low prevalence of ocular Chlamydia trachomatis infection and active trachoma in the western division of Fiji. PLoS Negl Trop Dis. 2016;10(7):e0004798.

27. Pickering $\mathrm{H}$, Holland M, Last A, Burton M, Burr S. Evaluation of a Chlamydia trachomatis-specific, commercial, real-time PCR for use with ocular swabs. Parasit Vectors. 2018. In press

28. Affymetrix. GeneChip human Transcriptome Array 2.0 datasheet. 2015. Available at: https://assets.thermofisher.com/TFS-Assets/LSG/brochures/hta_ array_2_0_datasheet.pdf. Accessed 20 July 2017.

29. R Core Team. R: a language and environment for statistical computing. R foundation for statistical computing; 2014.

30. Gentleman R, Carey V, Bates DM, Bolstad B, Dettling M, Dudoit S, et al. Bioconductor: open software development for computational biology and bioinformatics. Genome Biol. 2004:5(10):R80.

31. Carvalho BS, Irizarry RA. A framework for oligonucleotide microarray preprocessing. Bioinformatics. 2010;26(10):2363-7.

32. Smyth GK. Linear models and empirical Bayes methods for assessing differentia expression in microarray experiments. Stat Appl Genet Mol Biol. 2004:3(1):1-25.

33. Ritchie M, Phipson B, Wu D, Hu Y, Law C, Shi W, et al. Limma powers differential expression analyses for RNA-sequencing and microarray studies. Nucleic Acids Res. 2015;43(7):e47. 
34. Cui X, Loraine AE, Salit M, Cam M, Athey B. Consistency analysis of redundant probe sets on Affymetrix three-prime expression arrays and applications to differential mRNA pProcessing. PLoS One. 2009;4(1):e4229.

35. McCarthy DJ, Smyth GK. Testing significance relative to a fold-change threshold is a TREAT. Bioinformatics. 2009;25(6):765-71.

36. Kirkwood B, Sterne JA. Essential medical statistics. Oxford: Blackwell Publishing Ltd; 2003.

37. Venables W, Ripley B. Modern applied statistics with S. 4th ed. New York: Springer-Verlag; 2002.

38. Huang DW, Sherman BT, Lempicki RA. Systematic and integrative analysis of large gene lists using DAVID bioinformatics resources. Nat Protoc. 2008:4(1): 44-57.

39. Kanehisa M, Furumichi M, Tanabe M, Sato $Y$, Morishima K. KEGG: new perspectives on genomes, pathways, diseases and drugs. Nucleic Acids Res. 2017:45(D1):D353-61.

40. Ramadhani AM, Derrick T, Macleod D, Massae P, Mtuy T, Jeffries D, et al. Immunofibrogenic gene expression patterns in Tanzanian children with ocular Chlamydia trachomatis infection, active trachoma and scarring: baseline results of a four-year longitudinal study. Front Cell Infect Microbiol. 2017;7:406.

41. Zheng X, Yao J, Li B. Expression of TSLP and downstream molecules IL-4, IL5 , and IL-13 on the eye surface of patients with various types of allergic conjunctivitis. J Ophthalmol. 2016;2016:5072781.

\section{Submit your next manuscript to BioMed Central} and we will help you at every step:

- We accept pre-submission inquiries

- Our selector tool helps you to find the most relevant journal

- We provide round the clock customer support

- Convenient online submission

- Thorough peer review

- Inclusion in PubMed and all major indexing services

- Maximum visibility for your research

Submit your manuscript at www.biomedcentral.com/submit 